\title{
O JOGO, O ESPORTE E O LAZER NA CONSTITUIÇÃO DO IDEÁRIO AMBIENTAL ${ }^{1}$
}

\author{
Recebido em: 07/07/2014
}

Aceito em: 02/03/2015

\author{
Cae Rodrigues ${ }^{2}$ \\ Universidade Federal de Sergipe (UFS) \\ Sergipe - Aracaju - SE - Brasil
}

RESUMO: Distintos discursos relacionados à problemática socioambiental emergem como consequência da inserção da dimensão ambiental em diferentes campos do conhecimento. Levando em consideração a força histórica do jogo, do esporte e do lazer como fenômenos socioculturais no campo da educação física, o objetivo desse artigo é analisar como esses fenômenos influenciam a constituição do ideário ambiental partindo dos discursos que emergem nas relações entre o campo da educação física e o campo ambiental. Para tanto, o corpus de análise foi composto por produções científicas que abordam a inserção da dimensão ambiental na educação física no Brasil. De maneira geral, os resultados da Análise Textual Discursiva sobre o corpus da pesquisa evidenciaram que as influências dos jogos, esportes e atividades em contextos de lazer na constituição do ideário ambiental se manifestam de maneira ainda bastante rudimentar.

PALAVRAS CHAVE: Meio Ambiente. Educação Física e Treinamento. Educação. Atividades de Lazer.

\section{GAMES, SPORTS, LEISURE AND THE CONSTITUTION OF THE ENVIRONMENTAL IDEAL}

ABSTRACT: Distinct discourses related to the socioenvironmental issue emerge from the insertion of the environmental dimension in different fields of knowledge. Considering the historical force of games, sports and leisure as sociocultural phenomena in the field of physical education, the aim of this article is to analyze how these phenomena influence the constitution of environmental ideals considering, more broadly, discourses that emerge from dialogues between the physical education and the environmental fields. To this end, the corpus of analysis comprised articles in scientific journals that address the insertion of the environmental dimension in physical education in Brazil. In general, the results of the Discursive Textual Analysis on the researched corpus showed that the influence of games, sports and activities in leisure contexts in the constitution of environmental ideals is still quite rudimentary.

\footnotetext{
$1{ }^{*} \mathrm{O}$ presente trabalho foi realizado com apoio do CNPq, Conselho Nacional de Desenvolvimento Científico e Tecnológico - Brasil.

${ }^{2}$ Professor Adjunto do Departamento de Educação Física da Universidade Federal de Sergipe (UFS).
} 
KEYWORDS: Environment; Physical Education and Training; Education. Leisure Activities.

\section{Introdução e Métodos}

A composição da questão socioambiental está associada, em grande parte ${ }^{3}$, às questões particulares de cada campo científico-acadêmico, uma vez que a incorporação da dimensão ambiental por diferentes campos do conhecimento gera elementos para a edificação de diferentes conjuntos de discursos e significados sobre a problemática socioambiental. Esse fenômeno se torna ainda mais relevante com a crescente legitimação do ideário interdisciplinar da educação ambiental ${ }^{4}$ e da sustentabilidade nas últimas décadas, ideário que ganha força (no contexto dos embates de força que fazem parte da constituição/legitimação das estruturas sociais), num primeiro momento, em conferências e documentos das Nações Unidas e, posteriormente, pela emergência de "novos" /transformados discursos científicos e documentos governamentais locais/nacionais que incorporam os valores e ética ambientais. No Brasil, por exemplo, as questões ambientais aparecem entre os temas transversais (Meio Ambiente) propostos pelos PCN (BRASIL, 1998a), ideia reforçada pelas novas Diretrizes Curriculares Nacionais para o Ensino Médio (BRASIL, 2012) ao resgatarem a ideia da transversalidade da temática ambiental definindo, em seu $5^{\circ}$ artigo, a "sustentabilidade ambiental como meta universal". Nesse sentido, os discursos têm de ser analisados tanto

\footnotetext{
${ }^{3}$ Sugere-se a leitura de Lopes (2006) para melhor compreensão sobre as principais influências na constituição da questão ambiental.

${ }^{4}$ Há uma série de tensões discursivas no âmbito internacional em torno de diferentes termos atribuídos à construção/institucionalização do "ambiental" no contexto educativo (educação ambiental, educação sustentável/para a sustentabilidade, educação para o desenvolvimento sustentável, alfabetização/letramento ambiental), especialmente considerando a transição de um discurso que reconhece apenas os aspectos "biofísicos" do ambiente para discursos que englobam também os aspectos socioeconômicos e culturais. Essas tensões não serão abordadas nesse artigo, considerando a limitação de caracteres e o foco central do trabalho. Para leitura mais aprofundada sobre o tema sugere-se a leitura de Stubbs; Schapper, 2011; O'Connell et al., 2005; Moore, 2005; Down, 2006; Kyburz-Graber e col., 2006; Sherren, 2008; Johnson, 2011; Francis, 2011.
} 
a partir das condições contextuais que estão na base da sua formulação e disseminação como a partir das referências, estruturas e dinâmicas que fazem funcionar cada campo disciplinar específico (FARIAS, 2008).

Justificado pelas considerações do parágrafo anterior, o objetivo central da pesquisa apresentada nesse artigo foi investigar as sinergias emergentes entre o discurso ambiental e o campo da educação física. Tendo em vista a amplitude dos resultados finais da pesquisa, decidiu-se por um foco mais específico na composição desse artigo: a influência do jogo, do esporte e do lazer nas propostas de inserção da dimensão ambiental na educação física e, mais amplamente, na composição do ideário ambiental.

O corpus de análise foi composto por produções científicas (resultado de pesquisas) que abordam a inserção da dimensão ambiental na educação física no Brasil. A escolha do corpus se justifica pela significância da pesquisa como capital simbólico institucionalizado ${ }^{5}$ sustentado pela força do campo científico/acadêmico e o papel protagonista que desempenha no reconhecimento/legitimação dos símbolos/estruturas que constituem os fenômenos socioculturais. A escolha por discursos publicados em periódicos científicos se justifica pelo "prestígio" que possuem (especialmente no universo acadêmico), uma vez que são submetidos à avaliação de atores que são reconhecidos/legitimados como especialistas em suas áreas, consequentemente legitimando esses discursos como expressivos para o desenvolvimento da área. Essa legitimidade é essencial para que o discurso extrapole as fronteiras do universo acadêmico e se insira em outras esferas sociais.

Os seguintes critérios foram usados para a seleção dos periódicos que fizeram parte da pesquisa: (a) são reconhecidos nacionalmente como veículos de divulgação

\footnotetext{
${ }^{5}$ Compreende-se por institucionalização o processo pelo qual uma sociedade desenvolve suas próprias estruturas de funcionamento (FARIAS, 2008).
} 
científica na área de educação física, estando listados no Sistema Integrado da CAPES na Área de Avaliação "Educação Física" ou "Interdisciplinar"; (b) possuem banco de dados digitalizado de livre acesso com possibilidade de pesquisa por palavra chave; (c) apresentam uma descrição de "foco e escopo" com abertura para a possível publicação de artigos com ênfase em educação física, meio ambiente e educação ambiental. Não foi definido, a priori, um espaço temporal para a seleção dos artigos. Esse espaço foi definido em cada periódico pela disponibilização de seu banco de dados digitalizado. Seguindo esses critérios, uma lista de 28 periódicos foi elaborada.

Uma vez selecionados os periódicos de acordo com os critérios adotados para a pesquisa, foram realizadas buscas nos bancos de dados digitais de cada periódico utilizando a palavra chave "Educação Física" em combinação com as palavras-chave "Meio Ambiente", “Ambiental”, “Ambientalização", "Natureza", "Sustentabilidade” e “Desenvolvimento Sustentável". Mesmo reconhecendo que a amostra resultante possa não apresentar a totalidade de produções sobre o tópico analisado (a inserção da dimensão ambiental na educação física), compreende-se que os critérios adotados para a pesquisa possibilitaram uma representativa amostra dessas produções ${ }^{6}$. Os resultados são apresentados no quadro a seguir pela ordem em que os artigos foram encontrados nos respectivos periódicos, ou seja, seguindo a organização do Sistema Integrado da CAPES, que apresenta os periódicos em ordem alfabética ${ }^{7}$ :

\footnotetext{
6 Osborne et al. (2011b) também apresentam uma análise de artigos sobre meio ambiente e sustentabilidade publicados em periódicos nacionais de educação física. Apesar de não concordarmos com alguns critérios de seleção adotados nos procedimentos de coleta de dados, o artigo apresenta interessantes dados quantitativos sobre a evolução da temática em periódicos nacionais.

${ }^{7}$ A amostra não inclui artigos com autoria ou co-autoria do autor desse artigo. A escolha pela exclusão desses artigos da amostra se justifica pela possibilidade de conflito de interesse que se apresentaria diante de uma análise de textos de própria autoria.
} 
Quadro 1: Produções científicas que apresentam propostas de inserção da dimensão ambiental na educação física no Brasil

\begin{tabular}{|c|c|c|c|c|}
\hline & Título do artigo & Autor(es) & Periódico & $\begin{array}{l}\text { Ano de } \\
\text { Publicacão }\end{array}$ \\
\hline Texto 1 & $\begin{array}{l}\text { A Educação Ambiental na } \\
\text { formação de professores de } \\
\text { Educação Física: uma emergente } \\
\text { conexão }\end{array}$ & $\begin{array}{lll}\text { Francisco } & \text { J. } & \text { P. } \\
\text { TAVARES } & & \end{array}$ & $\begin{array}{l}\text { Lecturas } \\
\text { Educación Física } \\
\text { y Deportes }\end{array}$ & 2003 \\
\hline Texto 2 & 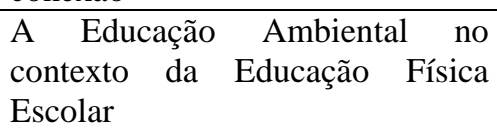 & $\begin{array}{l}\text { José E. N. VARGAS; } \\
\text { Francisco } \quad \text { J. P. } \\
\text { TAVARES }\end{array}$ & $\begin{array}{l}\text { Lecturas } \\
\text { Educación Física } \\
\text { y Deportes }\end{array}$ & 2004 \\
\hline Texto 3 & $\begin{array}{l}\text { Educação Física escolar e meio } \\
\text { ambiente: reflexões e aplicações } \\
\text { pedagógicas }\end{array}$ & $\begin{array}{l}\text { Luiz H. RODRIGUES; } \\
\text { Suraya C. DARIDO }\end{array}$ & $\begin{array}{l}\text { Lecturas } \\
\text { Educación Física } \\
\text { y Deportes }\end{array}$ & 2006 \\
\hline Texto 4 & $\begin{array}{l}\text { Educação física, esporte e lazer na } \\
\text { natureza: preservação, modismo, } \\
\text { apologia. Será tudo isso? }\end{array}$ & $\begin{array}{l}\text { Disalda M. T. LEITE; } \\
\text { Carlos A. CAETANO }\end{array}$ & Motrivivência & 2004 \\
\hline Texto 5 & $\begin{array}{l}\text { A Educação Física frente a } \\
\text { temática ambiental: alguns } \\
\text { elementos teórico-metodológicos }\end{array}$ & $\begin{array}{l}\text { Fabiano W. SILVA; } \\
\text { Ana M. SILVA; } \\
\text { Humberto } \quad \text { L. D. } \\
\text { INÁCIO }\end{array}$ & Motrivivência & 2008 \\
\hline Texto 6 & $\begin{array}{l}\text { Educação física na década da } \\
\text { educação para o desenvolvimento } \\
\text { sustentável }\end{array}$ & $\begin{array}{l}\text { Renata OSBORNE; } \\
\text { Washington } \\
\text { BATISTA }\end{array}$ & Motriz & 2010 \\
\hline Texto 7 & $\begin{array}{l}\text { Cultura de movimento: reflexões } \\
\text { a partir da relação entre corpo, } \\
\text { natureza e cultura }\end{array}$ & $\begin{array}{lll}\text { Marina I. } & \text { B. } & \text { S. } \\
\text { MENDES; } & & \\
\text { Terezinha } & & \text { P. } \\
\text { NÓBREGA } & & \end{array}$ & Pensar a Prática & 2009 \\
\hline Texto 8 & $\begin{array}{l}\text { Prática pedagógica em educação } \\
\text { física e a educação ambiental }\end{array}$ & $\begin{array}{l}\text { Maristela S. SOUZA; } \\
\text { Giane S. LARA }\end{array}$ & Pensar a Prática & 2011 \\
\hline Texto 9 & $\begin{array}{l}\text { Educação física, esporte } \\
\text { desenvolvimento sustentável }\end{array}$ & $\begin{array}{l}\text { Renata OSBORNE; } \\
\text { Carlos A. F. da SILVA; } \\
\text { Sebastião J. VOTRE }\end{array}$ & Pensar a Prática & 2011 \\
\hline Texto 10 & $\begin{array}{l}\text { Educação física no ensino médio } \\
\text { e as discussões sobre meio } \\
\text { ambiente: um encontro necessário }\end{array}$ & $\begin{array}{lr}\text { Simone } & \text { M. } \\
\text { GUIMARÃES } & \mathrm{e} \\
\text { colaboradores } & \end{array}$ & $\begin{array}{ll}\text { Revista } & \\
\text { Brasileira } & \text { de } \\
\text { Ciências } & \text { do } \\
\text { Esporte } & \end{array}$ & 2007 \\
\hline Texto 11 & $\begin{array}{l}\text { Educação física, meio ambiente e } \\
\text { aventura: um percurso por vias } \\
\text { instigantes }\end{array}$ & $\begin{array}{l}\text { Alcyane MARINHO; } \\
\text { Humberto } \quad \text { L. D. D. } \\
\text { INÁCIO }\end{array}$ & $\begin{array}{l}\text { Revista } \\
\text { Brasileira } \\
\text { Ciências } \\
\text { Esporte }\end{array}$ & 2007 \\
\hline Texto 12 & $\begin{array}{l}\text { Educação ambiental e educação } \\
\text { física: possibilidades para a } \\
\text { formação de professores }\end{array}$ & $\begin{array}{l}\text { Soraya } \\
\text { DOMINGUES; } \\
\text { Elenor KUNZ; } \\
\text { Lísia C. G. de ARAÚJO }\end{array}$ & $\begin{array}{l}\text { Revista } \\
\text { Brasileira } \\
\text { Ciências } \\
\text { Esporte }\end{array}$ & 2011 \\
\hline Texto 13 & $\begin{array}{l}\text { Implementação } \text { da educação } \\
\text { ambiental na graduação de } \\
\text { professores de educação física: } \\
\text { uma reflexão }\end{array}$ & $\begin{array}{l}\text { Francisco } \quad \text { J. } \quad \text { P. } \\
\text { TAVARES; } \\
\text { Maria I. C. LEVY }\end{array}$ & $\begin{array}{l}\text { Revista } \\
\text { Eletrônica do } \\
\text { Mestrado em } \\
\text { Educação } \\
\text { Ambiental } \\
\end{array}$ & 2001 \\
\hline
\end{tabular}


O corpus da pesquisa foi analisado seguindo a proposta de Análise Textual Discursiva (MORAES, 2003), metodologia que compreende os seguintes passos: a) desconstrução e unitarização - essencialmente um processo de desmontagem dos textos destacando elementos constituintes do corpus em busca de sentidos e relações com o foco principal da investigação; b) estabelecimento de relações ou categorização implica em construir relações entre as unidades de base combinando-as e classificandoas no sentido de compreender como esses elementos unitários podem ser reunidos na formação de conjuntos mais complexos; c) metatexto ou captação de um novo emergente - apresentação de uma compreensão renovada do todo a partir dos elementos construídos ao longo das etapas anteriores. Desse modo, com base nas unidades de significado destacadas do corpus da pesquisa e em referenciais historicamente legitimados nos campos da educação ambiental e da educação física, buscou-se a construção de "argumentos centralizadores" em referência aos objetivos da pesquisa.

Para facilitar a organização das unidades cada uma foi caracterizada por um código indicativo de sua origem dentro de cada texto. Essa codificação foi feita atribuindo um número a cada documento do corpus (seguindo a numeração apresentada no Quadro 1) e um segundo número para cada uma das unidades de significado destacada no texto. Assim, o texto codificado com o número 1 (Texto 1), por exemplo, deu origem às unidades (1.1), (1.2), etc.; o documento codificado com o número 2 (Texto 2) deu origem as unidades (2.1), (2.2), etc., e assim por diante.

De maneira geral, apesar de escassas e esparsas, evidenciando sua posição ainda bastante periférica, as propostas de inserção de questões ambientais na educação física apresentam um movimento particular que se constrói na intersecção do campo ambiental com o campo da educação física e de seus subcampos ou campos com os 
quais historicamente dialoga, como, por exemplo, esporte, lazer e turismo. Desse movimento originam-se novos/diferentes/ "alternativos" olhares que podem gerar questionamentos/transformações dos paradigmas dominantes que fazem parte da construção histórica desses campos, potencialmente gerando novos/diferentes embates de força e consequentes maneiras de pensar/agir. A seguir serão apresentados os resultados da pesquisa que fazem referência aos objetivos desse artigo, buscando expor algumas significativas influências do jogo, do esporte e do lazer nas propostas de inserção da dimensão ambiental na educação física e, mais amplamente, na composição do ideário ambiental ${ }^{8}$.

\section{Algumas considerações geo-culturais/históricas sobre jogo, esporte e lazer}

Compreendendo as possibilidades de inserção da dimensão ambiental na educação física, jogos, esportes e atividades em contextos de lazer aparecem com frequência nas propostas apresentadas no corpus analisado. De modo geral, aparecem como potenciais espaços para o questionamento de paradigmas vigentes, especialmente envolvendo atuais questões do campo ambiental e associando-se, predominantemente, às atividades (de aventura) na natureza. Tais propostas colocam em evidência uma fervorosa discussão que caminha à sombra da evolução das teorias críticas (especialmente a partir do final da década de 1970): considerando as limitações impostas pela naturalização de paradigmas históricos, como, por exemplo, os associados à emergência e evolução sociopolítica dos jogos, dos esportes e do lazer, quais são as reais possibilidades críticas (questionadoras de paradigmas vigentes) de propostas associadas a esses contextos? Para compreender melhor essa discussão algumas

\footnotetext{
${ }^{8}$ A pesquisa completa está publicada na Tese de Doutorado do autor (RODRIGUES, 2013).
} 
questões geo-culturais/históricas sobre a emergência e evolução sociopolítica dos jogos, dos esportes e do lazer serão apresentadas nos próximos parágrafos.

De acordo com os PCN para o terceiro e quarto ciclos do ensino fundamental em educação física (BRASIL, 1998b), entre as correntes/tendências filosóficas, políticas, científicas e pedagógicas que influenciaram a constituição da educação física no século XX destacam-se (especialmente até a década de 1950) as influências provenientes da filosofia positivista, da área médica (por exemplo, o higienismo) e de interesses militares (nacionalismo, instrução pré-militar), além dos modelos de práticas corporais "importados" da Europa, como os sistemas ginásticos alemão e sueco e o método francês entre as décadas de 1910 e 1920 e o método desportivo generalizado nas décadas de 1950 e 1960. Nesse sentido, a representatividade dos jogos e dos esportes associa-se, num primeiro momento, ao desenvolvimento físico (motor/cognitivo e de habilidades/capacidades) do indivíduo, acompanhando a lógica materialista/higienista/militarista que sustentava a base primordial da área.

Com o fortalecimento das teorias críticas em contextos pedagógicos, atividades associada ao jogo, esporte e lazer "ganham" (especialmente a partir da década de 1980) um caráter educacional acompanhando a lógica da "dialogicidade" (especialmente em contextos "latinos"), compreendendo o diálogo como fenômeno de interação intersubjetiva entre seres humanos que se dá não só de maneira verbal, mas por todo tipo de manifestação corporal que possibilita a expressão e a compreensão entre indivíduos que interagem. Diante dessa lógica compreende-se a motricidade ${ }^{9}$ humana

\footnotetext{
${ }^{9}$ Segundo Manuel Sérgio (1999) trata-se a motricidade de "[...] movimento intencional da transcendência, ou seja, o movimento de significação mais profunda" (p.17), na qual o essencial "[...] é a experiência originária, donde emerge também a história das condutas motoras do sujeito, dado que não há experiência vivida sem a intersubjetividade que a práxis supõe" (p.17).
} 
"encharcada" de intencionalidade ${ }^{10}$, que se manifesta pela ação entre indivíduos que interagem uns-com-os-outros e com-o-mundo. Nesse contexto, os jogos, esportes e atividades em contextos de lazer aparecem como elementos "privilegiados" na constituição dos espaços de ensino e de aprendizagem (no contexto escolar e não escolar) ou, de maneira mais ampla, de com-vivência ${ }^{11}$.

Os "jogos tradicionais" e os "jogos cooperativos" são exemplos do movimento descrito no parágrafo anterior e que são referenciados no corpus da pesquisa apresentada nesse artigo. Sobre os jogos tradicionais (jogos com origem em culturas "tradicionais", no sentido de primordiais/originárias, por exemplo, culturas indígenas), Silva e col. (1989, p.71) afirmam que:

A perda da experiência, da possibilidade da reflexão, da memória como suporte da identidade, do enraizamento cultural e da participação do coletivo, o desaparecimento de todos esses elementos, resultado da modernização, significou o advento do indivíduo desmemoriado, sem vínculo com a tradição, que vive os sobressaltos e choques da vida cotidiana sem a possibilidade de reflexão.

Como possível meio para a reversão dessa situação, assim como para o potencial questionamento de alguns modos de "pensar" e de "agir" associados à estrutura social vigente, as autoras destacam o valor dos jogos tradicionais:

Se por um lado temos a cultura de massa que promove o consumo e a utilização dos objetos como descartáveis e de fácil substituição apelando para que cada indivíduo reproduza o modo de vida capitalista, de outro lado temos as brincadeiras tradicionais que contém elementos da tradição e que podem ser ressignificados no presente e dar inteligibilidade e sentido à história de cada um, bem como à história do coletivo (SILVA et al. 1989, p.125).

\footnotetext{
10 "Comportamento corpóreo-mundano e existencial, no qual se constitui e reconstitui o mundo significado" (FIORI, 1986, p.4).

11 O termo "com-vivência" é apresentado dessa maneira objetivando a ênfase no caráter humano implícito na expressão, ou seja, o "viver com", que significa considerar a complexa teia de relações de seres humanos sendo-uns-com-os-outros. O caráter dinâmico da expressão também deve ser salientado, apresentado especialmente pelo uso do hífen (usual principalmente na fenomenologia), pois homens e mulheres não são no mundo como objetos estáticos, estão sendo ao mundo num movimento constante e transformador (STEVAUX; RODRIGUES, 2012).
} 
Na mesma direção, os jogos cooperativos também ganharam legitimidade pelo seu potencial crítico, sendo caracterizados como:

[...] jogos com uma estrutura alternativa onde os participantes jogam com o outro, e não contra o outro. Joga-se para superar os desafios do próprio jogo e o não o outro, joga-se por gostar do jogo. Geralmente são jogos já conhecidos, com regras adaptadas, onde se procura desenvolver valores de solidariedade e cooperação, onde os praticantes tendem a se sentir pessoalmente valorizados e apoiados por seus colegas e passam a preocuparse com a aprendizagem de seus pares, sentimento que acaba contagiando todo o grupo. Os Jogos Cooperativos são jogos de compartilhar, unir pessoas, jogos que eliminam o medo e o sentimento de fracasso "e que reforçam a confiança em si mesmo". São jogos onde o esforço cooperativo é necessário para atingir um objetivo comum e não fins mutuamente exclusivos (BROTTO, 1997, p.66).

Do ponto de vista cultural, o jogo apresenta-se como um dos principais meios de educação lúdica para a aprendizagem de habilidades e a incorporação de valores a partir de experiências espaço-temporais corpóreas/perceptivas que se manifestam pela motricidade ("encharcada" de intencionalidade) entre indivíduos que interagem unscom-os-outros e com-o-mundo. Como fenômeno lúdico, uma das mais marcantes características pedagógicas do jogo estaria associada a uma aparente fuga do cotidiano, uma vez que seus participantes passariam a vivenciar uma situação que não faz parte de suas vidas cotidianas, mesmo que joguem todos os dias. No entanto, compreendendo que não seria possível desmembrar o momento do jogo da vida do sujeito que o pratica, uma vez que a vida não para no momento do jogo (enquanto se joga se vive), o que muda é a atitude daquele que joga, pois ele se dispõe a uma prática que contribui para ampliação de situações diferenciadas das situações cotidianas (STEVAUX; RODRIGUES, 2009).

Dessa forma, apesar do jogo ser visto como um momento isolado, tendo suas resultantes consideradas apenas durante a partida ou brincadeira, os jogadores carregam para o jogo seus valores e preconceitos. Nesse sentido, durante a execução do jogo não é incomum a manifestação de valores externos ao jogo, como, por exemplo, a exclusão 
(mesmo que involuntária/naturalizada) condicionada por características sociais (como gênero e raça) ou físicas (como as associadas à obesidade ou fragilidade de um indivíduo). Esses fatores levam à compreensão de que os valores e preconceitos do indivíduo que joga podem ser questionados na preparação para o jogo, no momento do jogo e nos momentos de com-vivência após o jogo e isso seria um elemento essencial na constituição do jogo como espaço privilegiado para o desenvolvimento de processos educativos. Por outro lado, o não questionamento dos valores e preconceitos do indivíduo que joga pode transformar o jogo em mais uma ferramenta de legitimação de forças socioestruturais dominantes.

Ao mesmo tempo em que é possível identificar esse movimento que defende o jogo e o esporte como meios potencialmente críticos para abordagens pedagógicas, não são raras, por outro lado, críticas relacionadas ao caráter de desenvolvimento "físico" do indivíduo que se encontra nas raízes da educação física, assim como à evolução do "esporte espetáculo" e do profissionalismo da performance e a associação dessas evoluções com a indústria do entretenimento, evidenciando o caráter potencialmente “alienante" dos jogos e dos esportes. Soares (2001, p.50), por exemplo, afirma que:

\footnotetext{
A Educação Física, filha do liberalismo e do positivismo, deles absorveu o gosto pelas leis, pelas normas, pela hierarquia, pela disciplina, pela organização da forma. Do liberalismo forjou suas 'regras' para os esportes modernos (que, não por acaso, surgiram na Inglaterra), dando-lhes a aparência de serem 'universais' e, deste modo, permitindo a todos ganhar no jogo e vencer na vida pelo seu próprio esforço. Do positivismo, absorveu com muita propriedade, sua concepção de homem como ser puramente biológico e orgânico, ser que é determinado por caracteres genéticos e hereditários, que precisa ser 'adestrado', 'disciplinado'. Um ser que se avalia pelo que resiste.
}

Essa mesma dualidade contraditória encontrada no desenvolvimento de propostas pedagógicas por meio dos esportes e dos jogos também pode ser encontrada em propostas pedagógicas por meio de atividades em contextos de lazer. As primeiras 
décadas do século XX foram marcadas pela consolidação do desenvolvimento cultural e pelo fortalecimento de uma sociedade regida pela produção industrial. Em uma época de "renovação" da tradição cultural essa se desenvolveu com certa vulnerabilidade frente à nova fase de produção e do consumo, situação que sem dúvida favoreceu a grande influência de uma indústria cultural que gerava necessidades padronizadas para maior facilidade no consumo, dificultando, assim, a superação de situações de conformismo (MARCELLINO, 2000).

Em movimento contrário a esses desenvolvimentos, o fortalecimento das teorias críticas em contextos pedagógicos associa aos contextos de lazer um caráter educacional acompanhando a lógica da "dialogicidade", da mesma forma em que ocorre com os jogos e atividades esportivas. Novamente evidencia-se a mesma contradição: por um lado, do ponto de vista cultural, contextos de lazer apresentam-se como possibilidade para a "educação lúdica" a partir de experiências espaço-temporais corpóreas/perceptivas que se manifestam pela motricidade; por outro lado, compreendendo a força histórica da indústria do entretenimento e o caráter potencialmente "alienante" de atividades em contextos de lazer (por exemplo, BRAMANTE，1998; PINTO，1998; CAMARGO，1998a; 1998b; MARCELLINO, 1998; 2000), dúvidas são levantadas em relação ao potencial crítico de abordagens pedagógicas em contextos de lazer (RODRIGUES, 2012a; 2012b).

Toda essa discussão acompanha a evolução mais recente das atividades esportivas e recreativas na natureza, criando frequentes contradições entre discursos que criticam os conservadorismos paradigmáticos associados ao jogo, ao esporte e ao lazer e, ao mesmo tempo, defendem as atividades esportivas e recreativas na natureza como meio para abordagens pedagógicas (inclusive no contexto ambiental). Eis a base da 
contradição: como fenômenos socioculturais, jogo, esporte e lazer carregam uma história e o ator envolvido em práticas nesses contextos tem "naturalizado" em si parte dessa história. Segundo Bracht (1997):

[...] muitos dos elementos característicos da sociedade moderna, no caso capitalista industrial, vão ser incorporados e/ou estão presentes no esporte: orientação para o rendimento e a competição, a cientifização do treinamento, a organização burocrática, a especialização de papéis, a pedagogização e o nacionalismo - este último sendo central para a expansão do esporte promovida pelo movimento olímpico (p.97). [...] Por sua vez, a orientação para o rendimento e o record, inscrevem-se na crença moderna do crescimento e progresso ilimitados (p.102).

Desse modo, propostas pedagógicas (críticas) por meio de atividades esportivas e recreativas (inclusive na natureza) que não reconheçam as possíveis limitações associadas aos contextos geo-culturais/históricos desses fenômenos socioculturais correm grande risco de não contemplarem seus objetivos.

Após a breve contextualização geo-cultural/histórica apresentada nessa parte do artigo, a seção seguinte será dedicada à análise mais específica das propostas de inserção da dimensão ambiental na educação física por meio de jogos, esportes e atividades em contextos de lazer destacadas do corpus da pesquisa apresentada nesse artigo.

\section{Esporte, jogo, lazer e a inserção da dimensão ambiental na educação física}

A ideia dos jogos (principalmente os cooperativos e "tradicionais"), dos esportes (principalmente os de aventura ou na natureza) e de atividades em contextos de lazer (novamente com ênfase nas de aventura ou na natureza) como veículos/meios para o desenvolvimento sustentável e para a educação ambiental aparece com frequência entre as unidades de significado destacadas do corpus da pesquisa. 
Segundo Osborne e Batista (2010, p.34 - Unidade 6.1), “[...] quanto à discussão sobre que atividades físicas são recomendadas para o Desenvolvimento Sustentável, destaca-se a necessidade de trabalhar não só os jogos cooperativos, tão indicados, mas também o esporte, que deve ser mais compreendido". Para uma "melhor compreensão" do esporte os autores apontam para a tensão entre os objetivos pedagógicos do esporte e os interesses do esporte de alto rendimento, conflito histórico abordado na seção anterior. Mais especificamente no contexto dos jogos cooperativos e dos jogos tradicionais os autores destacam o "jogar com o outro" inerente aos jogos cooperativos, assim como a potencial visão questionadora de alguns padrões modernos que podem ser desenvolvida a partir dessas atividades:

[...] estimular os jogos cooperativos, que trabalham com o princípio de "jogar com o outro" e não apenas "jogar contra o outro"; os jogos tradicionais, que valorizam a cultura regional e o legado de gerações passadas; o frescobol que é um jogo onde não há adversários e sim parceiros; e a capoeira, que é parte da história brasileira e apresenta uma visão de mundo questionadora de padrões da sociedade moderna ocidental (OSBORNE; BATISTA, 2010, p.34 - Unidade 6.3). [...] No mesmo sentido do frescobol, acrescentamos a peteca, que também é jogada por parceiros e é um jogo originado pela cultura indígena (OSBORNE; BATISTA, 2010, p.35 - Unidade 6.4).

Atribuindo importância aos jogos e ao esporte como "agentes" para o desenvolvimento sustentável os autores levam o leitor a compreender que ao mesmo tempo em que os jogos cooperativos e tradicionais são essenciais para a promoção de condutas solidárias, estimulando a com-vivência, cultivando o compromisso entre gerações e culturas e recuperando o espírito lúdico dos jogos perdido em parte com o advento dos esportes modernos, seria igualmente importante refletir sobre a questão da competitividade por meio de atividades esportivas, estendendo a discussão para os elementos presentes na sociedade que seguem os mesmos padrões dos esportes de rendimento (competitividade, individualidade, busca incessante pelo mérito, produtividade). Isso implicaria questionamentos sobre alguns dos mais consolidados 
padrões da sociedade moderna, entre eles alguns das principais tensões na relação ser humano-natureza.

Desse modo, a partir da compreensão do potencial crítico/questionador de jogos e atividades esportivas (assim como de outros fenômenos socioculturais atrelados ao movimento humano) e considerando que esses fenômenos fazem parte do conjunto de conteúdos que estariam, prioritariamente, associados à área da educação física, cria-se (supostamente) um significativo espaço para o desenvolvimento "práxico" de atividades potencialmente questionadoras de paradigmas vigentes (inclusive no campo ambiental) proveniente dos desenvolvimentos particulares da educação física. De acordo com Domingues; Kunz; Araújo (2011, p.567 - Unidade 12.4):

Portanto, estamos falando de conteúdos reconhecidos no cotidiano, na cultura, e que proporcionam o conhecimento do ambiente em que se vive e também o conhecimento da especificidade da Educação Física. Desta forma os fundamentos políticos, fisiológicos, sociológicos e pedagógicos de conteúdos culturais como danças, folguedos, jogos, ginástica, brincadeiras e atividades esportivas são trabalhados para proporcionar o conhecimento da Educação Física e do ambiente.

Essa argumentação forma a base para os discursos que defendem o desenvolvimento de jogos, esportes e atividades em contextos de lazer como meio para possíveis transformações na realidade vigente (inclusive no contexto ambiental) pela incorporação de novos/diferentes valores e pela construção de uma nova/diferente ética. Considerando possíveis transformações especificamente no âmbito das questões ambientais, esses discursos parecem estar predominantemente associados às atividades esportivas e recreativas (de aventura) na natureza, como destacam Guimarães et al. (2007, p.168 - Unidade 10.1): “os esportes da natureza, por exemplo, são excelentes possibilidades de fundir os conteúdos da educação física e a temática ambiental, buscando a vivência concreta de práticas essenciais à vida do ser humano". Mais especificamente sobre o potencial diferenciado dos esportes (de aventura) na natureza 
em relação ao "esporte espetáculo" (ou de rendimento) para a incorporação de valores

"alternativos" (novos/diferentes), Rodrigues e Darido (2006, p.3 - Unidade 3.5)

afirmam que:

Em oposição à vertente institucionalizada do esporte espetáculo em que preponderam as práticas mecanizadas, a eficácia do rendimento corporal e a produção de bens e serviços, os esportes de aventura buscam, segundo Costa (2000), resgatar os valores de beleza, auto-realização, liberdade, cooperação e solidariedade. É necessário, então, um olhar mais cuidadoso em relação à inserção dos esportes de aventura e as suas influências no cenário da cultura corporal de movimento.

No mesmo sentido, são apresentadas a seguir outras unidades de significado que

destacam o desenvolvimento de valores, atitudes e possíveis ações educativas em atividades esportivas e recreativas (de aventura) na natureza que, segundo os autores, possivelmente podem gerar transformações nas relações ser humano/sociedadenatureza.

O esporte de aventura, sobretudo aquele realizado junto à natureza, representa mais uma possibilidade de aproximação entre o indivíduo e o meio ambiente, devido à interação com os elementos naturais e as suas variações, como sol, vento, montanha, rios, vegetação densa ou desmatada, lua, chuva, tempestade, desencadeando atitudes de admiração, respeito e preservação (RODRIGUES; DARIDO, 2006, p.4 - Unidade 3.7).

[...] a relação seres humanos-natureza, por meio das atividades de aventura, como um espaço-tempo significativamente privilegiado para uma transformação do sujeito, da sociedade e das relações. Precisamos distanciarnos das dinâmicas perversas que apenas associam as atividades de aventura a alguma experiência no meio natural; temos de assumir uma "lógica ecológica", a qual, por sua vez, deve-se mostrar solidária, conservacionista, democrática e dialógica (MARINHO; INÁCIO, 2007, p.67 - Unidade 11.1).

Nós, em vez de lamentarmos a ausência de consciência ecológica, devemos propor uma agenda de ações educativas em que os esportistas se transformem em agentes de monitoração, denúncia de ações destrutivas e, sobretudo, mentores de melhoria de alguns aspectos críticos da realidade ambiental. Vias soterradas, pedras sob risco de rolarem, lixo acumulado em mananciais, ações criminosas de corte de árvores e uso de fogo em áreas de preservação, eis alguns dos pontos em que os praticantes de esportes podem contribuir efetivamente para a salvaguarda do ecossistema. (OSBORNE; SILVA; VOTRE, 2011a, p.10 - Unidade 9.1) [...] O papel predador de alguns esportes na natureza deve ser objeto de análise e discussão, com vistas à intervenção social (OSBORNE; SILVA; VOTRE, 2011a, p.10 - Unidade 9.2). 
De maneira geral as unidades apresentadas evidenciam como os discursos em torno das atividades esportivas e recreativas na natureza incorporaram tanto ideais de teorias ambientais preservacionistas (sensibilização em contato direto com a natureza para desencadeamento de atitudes de preservação; denúncia de ações destrutivas da natureza) como alguns dos principais pilares das teorias (ambientais) críticas e póscríticas (solidariedade; dialogicidade; ação democrática; consciência ética, estética e política) ${ }^{12}$. No entanto, são raros os questionamentos sobre as origens e interesses "por trás" desses discursos. Entre esses raros questionamentos destaca-se a Unidade 8.2, na qual as autoras afirmam que a possibilidade de atuação para a transformação:

[...] pode acontecer, no âmbito de ensino formal e informal da EF, começando com a problematização dos aspectos pedagógicos e valores que se apresentam no processo de desenvolvimento das novas práticas esportivas que se anunciam no contexto ambiental. A que discurso pedagógico/ideológico essas práticas servem? O que essas práticas trazem ou poderão trazer de novo e transformador para a área de conhecimento da EF? A EF não estará com esta prática contribuindo para reforçar o discurso oficial hegemônico da EA? (SOUZA; LARA, 2011, p.8).

Ainda segundo as autoras, as possibilidades da educação física para a educação ambiental compreendem uma ação que "[...] não apenas transmita conhecimentos ecológicos, mas represente uma proposta política de reflexão, debate e posicionamento sobre a relação homem e natureza e sua produção sociocultural" (SOUZA; LARA, 2011, p. 8 - Unidade 8.3).

Nessa mesma linha de questionamento crítico, há uma consideração interessante presente no corpus da pesquisa sobre a relação entre o acesso a práticas esportivas e em contextos de lazer e as questões ambientais. Práticas sociais que explicitem e reduzam relações discriminatórias apresentam-se como um dos elementos de maior convergência entre os diferentes discursos ambientais críticos e pós-críticos, especialmente como

\footnotetext{
12 Para leitura mais aprofundada sobre os desenvolvimentos críticos e pós-críticos dos discursos ambientais sugere-se a leitura de Payne e Rodrigues, 2012.
} 
consequência de representativos movimentos críticos globais como, por exemplo, o movimento feminista e a associação desses movimentos às questões de justiça social (PAYNE; RODRIGUES, 2012). Seguem duas unidades de significado que fazem afirmações nesse sentido:

\begin{abstract}
Outro grande tópico apresentado pelo tema transversal meio ambiente propõe-se analisar as diversas maneiras de relacionamento entre a sociedade e o meio ambiente. Uma interface promissora dentro dessa temática relaciona-se às reflexões sobre a extinção ou privatização dos espaços públicos destinados as atividades de lazer e recreação. Entender as razões históricas e estruturais responsáveis pela apropriação dos espaços públicos de lazer e buscar alternativas para assegurar condições mínimas de segurança e adequação bem como estratégias para a ampliação da oferta dos espaços por parte dos órgãos públicos caracterizam-se como uma ação pedagógica significativa (RODRIGUES; DARIDO, 2006, p.2 - Unidade 3.2).

É preciso uma reorientação das práticas corporais às finalidades mais humanas, permitindo que a grande margem dos excluídos, como os deficientes físicos e pobres, por exemplo, possam ter acesso ao conhecimento e as oportunidades oferecidas por atividades esportivas e de lazer, que tem sido privilégio das minorias com poder econômico e que, deste modo, conseguem lutar contra os males da vida moderna, que se acentuam sobremaneira pela industrialização sem limites: o estresse, o sedentarismo que provoca a obesidade, os problemas cardíacos, de postura corporal, entre outros. Por outro lado, a EF tem se apresentado para muitos apenas pelos esportes veiculados através dos meios de comunicação de massa, onde a maior parte das pessoas passa de praticante a espectador (TAVARES, 2003, p.4 - Unidade 1.1).
\end{abstract}

$\mathrm{Na}$ segunda citação (Unidade 1.1) nota-se uma referência a potencial contribuição da educação física para dar subsídios a questões relacionadas à saúde. Como destacado na seção anterior, influências da área da saúde (por exemplo, o higienismo) estão atreladas à gênese da educação física no Brasil. Desse modo, fazem parte dos conteúdos primordiais da área tópicos associados à manutenção do "bem estar" (especialmente associado à execução de exercícios físicos sob slogans como “esporte é saúde”; mais recentemente as atividades na natureza também passam a adotar esse discurso), da saúde "física e mental" (em geral associado ao slogan "mente sã, corpo são", reiterando a base filosófica materialista fragmentária da área) e mesmo de hábitos de higiene corporal (uma vez que isso também estaria associado ao "corpo"). 
Apesar de (re)construções epistemológicas contemporâneas da educação física se apoiarem em outras grandes áreas, especialmente no contexto das ciências humanas, ainda há uma forte associação com a área da saúde e isso pode ser observado, inclusive, em outras unidades de significado destacadas do corpus de análise:

\begin{abstract}
Sobre as potencialidades da EF de contribuir para o Desenvolvimento Sustentável, destacamos a sua função de contribuir para o sistema educativo e para o crescimento da criança. Foi destacado, pelos participantes, o desejo de que a EF contribua para que as crianças adquiram hábitos de vida saudáveis tais como a prática regular de exercícios físicos e uma adequada nutrição (OSBORNE; BATISTA, 2010, p.35 - Unidade 6.5).

A interface entre a saúde e o meio ambiente abre significativas possibilidades pedagógicas em aulas de Educação Física e pode ser abordada como uma temática social. $\mathrm{O}$ entendimento de saúde deve estar vinculado a uma política pública, direcionada a toda a população e não a uma elite, a intervenção não esteja restrita a uma única ação (praticar atividade física), esquecendo os fatores sociais, econômicos, culturais, educacionais, etc. A concepção de saúde deve envolver a complexidade das relações entre o indivíduo e o meio ambiente, considerando as desigualdades sociais, fruto de má distribuição de renda (RODRIGUES; DARIDO, 2006, p.3 - Unidade 3.4).
\end{abstract}

Segundo Soares (2001), a influência do pensamento médico higienista na gênese da educação física brasileira pode ser em grande parte responsabilizada pela visão biologicista/naturalista ainda dominante na área. Tal linha de pensamento enxergava no exercício físico um hábito capaz de gerar saúde em si mesmo, com o potencial de tornar-se um "ato disciplinador" de gestos/vontades diante dos processos de desenvolvimento capitalista. Mais especificamente sobre a relação da educação física com hábitos de higiene pessoal destaca-se a influência do advogado baiano Rui Barbosa ainda no período final do Brasil Império. Segundo Ghiraldelli Júnior (1991), o advogado emitiu nessa época diversos pareceres expressando a necessidade da educação física enraizar em nossa juventude hábitos higiênicos. No entanto, mesmo tendo raízes associadas a visões biologicistas/naturalistas e até mesmo de dominação hegemônica (que em certa medida permanecem até os dias atuais; alguns diriam até predominantemente), é interessante notar nas unidades de significado apresentadas 
como os discursos da saúde também adotam elementos dos discursos críticos, como, por exemplo, a caracterização da interface entre a saúde e o meio ambiente como "temática social”, a redução de relações elitistas/discriminatórias e mesmo a urgência por visões mais holísticas e complexas.

\section{Considerações Finais}

A aquisição/incorporação/transformação de certos valores, especialmente em busca de uma "nova"/diferente ética (ambiental), é tema recorrente entre as produções analisadas, refletindo, aliás, discursos da área ambiental e da educação física (especialmente os que defendem atividades pedagógicas por meio de jogos, esportes e atividades em contextos de lazer). Há, no entanto, uma preocupação com a forma em que esses valores "alternativos" são apresentados, uma vez que são raras as discussões sobre a pluralidade de significados possíveis associados a tais valores. Por exemplo, o valor de "beleza" citado na Unidade 3.5 pode estar associado: a) à (re)construção da dimensão sensível pela valoração perceptiva/sensorial do ambiente a partir da reflexão "práxica" sobre as (complexas) relações entre a estética ambiental (e todas as suas possibilidades) e a agência humana (e todas as suas possibilidades), construção, aliás, considerada essencial pelos discursos ambientais críticos e, especialmente, pós-críticos (PAYNE; RODRIGUES, 2012); ou b) a padrões de beleza definidos/legitimados por relações socioestruturais de dominância que, sendo reproduzidos por atividades na natureza que se caracterizam como "alternativas"/modernas, são fortalecidos e ainda mais legitimados.

O mesmo tipo de questão poderia ser levantada sobre outros valores/atitudes destacados nos discursos, como, por exemplo, "admiração" e "respeito" (associado à 
uma educação estética do ambiente ou à símbolos de dominação?); "preservação", "conservacionista" ou "salvaguarda do ecossistema" (levando em consideração as questões inseridas dentro do contexto dos movimentos de justiça social/ambiental ou simplesmente reproduzindo discursos preservacionistas/naturalistas mais associados à práticas de greenwashing ${ }^{13}$ ?); e mesmo "solidário" ou "democrático" (levando em consideração as limitações dos discursos críticos diante da naturalização dos símbolos dominantes ou reproduzindo discursos idealistas?). Esse é um ponto de importante reflexão, considerando que "fragilidades" teóricas no sentido apontado podem enfraquecer os discursos que emergem nas sinergias entre o campo ambiental e o campo da educação física.

Analisando o conjunto de discursos apresentados, considerando tanto as referências associadas ao corpus de análise (apresentadas pelas unidades de significado) como as referências de outros autores (que possibilitam uma melhor contextualização histórica das questões apresentadas, especialmente em suas evoluções na área da educação física), o potencial pedagógico/educacional de uma atividade qualquer ou o desenvolvimento de práticas/teorias potencialmente questionadoras de paradigmas históricos/vigentes parece estar quase sempre envolto por certo dualismo de possibilidades. Todo fenômeno sociocultural possui uma contextualização geocultural/histórica e, em sua evolução, uma urgência por discursos atuais. Todo fenômeno sociocultural possui uma lógica histórica/vigente de dominância, assim como emergentes lógicas de contestação. Desse modo, mais importante do que a atividade em si (seja o jogo - "tradicional", cooperativo, competitivo; o esporte - ocidental,

\footnotetext{
${ }^{13} \mathrm{O}$ termo "greenwashing" (tradução literal seria algo como "lavagem verde") é usado na língua inglesa para se referir a uma estratégia de marketing "verde" maliciosamente/enganosamente usada para promover a percepção de que os objetivos e políticas de uma organização são ambientalmente corretas/amigáveis.
} 
tradicional, de aventura; as atividades em contextos de lazer; ou ainda outras manifestações da motricidade humana) parece ser a maneira em que essa atividade é conduzida, sendo que nos dois pólos opostos dentre múltiplas possibilidades se encontram a reprodução ou contestação dos aspectos de dominância.

Essa consideração se torna ainda mais significativa se inserirmos nesse contexto a força de paradigmas históricos em torno dos fenômenos socioculturais jogo, esporte e lazer que se manifestam, sobretudo, na conservação de símbolos de dominância. Por exemplo, voltando o foco à dependência histórica/cultural de indivíduos que buscam envolvimento em atividades em contextos de lazer à indústria do entretenimento, destaca-se a capacidade de adaptação desse mercado diante de discursos emergentes. Desse modo, se, por um lado, o fortalecimento do discurso ambiental pode (possivelmente) levantar questionamentos aos postulados dessa indústria, por outro lado oferece (certamente) um rico nicho para o contínuo desenvolvimento do mercado do lazer (RODRIGUES; SILVA, 2011; RODRIGUES, 2012b), consequentemente ampliando a produção e o consumo acríticos do lazer.

Questões similares são levantadas em relação aos jogos e esportes, especialmente considerando o histórico potencial econômico e político desses fenômenos como "espetáculos" populares, possibilitando reflexões desde os povos mais antigos das Américas, passando pelos "jogos de guerra" e olímpicos desde a Grécia antiga e a política de "pão e circo" desde a Roma antiga, até as implicações sociopolíticas dos grandes espetáculos modernos e contemporâneos. Sim, discursos emergentes (como o ambiental) podem levantar "novos" questionamentos aos postulados paradigmáticos que cercam as históricas relações sociopolíticas dos jogos e 
dos esportes, mas também podem se transformar em mais uma ferramenta de “modernização" e consequente propagação desses mesmos postulados.

Voltando à questão central proposta nesse artigo - de que forma os jogos, esportes e atividades em contextos de lazer contribuem para a constituição do ideário ambiental? - tal contribuição parece ser ainda muito rudimentar. As produções analisadas parecem se preocupar ainda em "apresentar" a temática ambiental para os atores da área da educação física, resultando em textos que abrangem uma grande diversidade de temas e tópicos de maneira relativamente superficial. Além disso, se os resultados da pesquisa apresentada nesse artigo mostram que há um movimento (mesmo que periférico) de inserção do discurso ambiental na educação física, o mesmo não acontece na direção oposta, sendo que são muito raros os atores da educação física que circulam em eventos e publicam em veículos do campo ambiental. Desse modo, se há na prática um crescente movimento de jogos, esportes e atividades em contextos de lazer que envolve a dimensão ambiental e, com isso, "novas" possibilidades de reflexões/questionamentos sobre os postulados paradigmáticos que envolvem todos esses fenômenos socioculturais, os caminhos para a compreensão e divulgação dessas possibilidades ainda são bastante estreitos.

Concluindo, se a publicação de artigos mais "abrangentes" (que abrangem uma grande diversidade de temas e tópicos) sobre a inserção das questões ambientais na educação física foi de grande importância num primeiro momento, legitimando (mesmo que perifericamente) esse discurso (pelo menos na área da educação física), há no presente momento a necessidade de estudos mais específicos que aprofundem as discussões sobre como os novos desenvolvimentos que cercam os discursos críticos/pós-críticos da área ambiental refletem sobre as especificidades da área da 
educação física (incluindo jogos, esportes e lazer, como proposto nesse artigo) e viceversa. Nesse processo há uma real possibilidade de que sinergias entre o campo ambiental e o campo da educação física contribuam para discussões que busquem mais modestamente "re-imaginar" alguns dos interesses do conhecimento, as relações de poder e as condições opressivas associadas às organizações socioestruturais.

\section{REFERENCIAS}

BRACHT, V. Sociologia crítica do esporte: uma introdução. Vitória: CEFD-UFES, 1997.

BRAMANTE, A. C. Lazer: concepções e significados. Licere, v.1, n.1, p.9-17, 1998.

BRASIL. Ministério da Educação. Conselho Nacional de Educação. Resolução no.2, de 30 de Janeiro 2012. Define Diretrizes Curriculares Nacionais para o Ensino Médio. Brasília: MEC/CNE, 2012.

. Ministério da Educação. Secretaria de Educação Fundamental. Parâmetros Curriculares Nacionais. Brasília, DF: MEC/SEF, 1998a.

Ministério da Educação. Secretaria de Educação Fundamental. Parâmetros Curriculares Nacionais - terceiro e quarto ciclos do Ensino Fundamental: Educação física. Brasília: MEC/SEF, 1998b.

BROTTO, F. O. Jogos cooperativos: se o importante é competir, o fundamental é cooperar. Santos: Re-novada, 1997.

CAMARGO, L. O. L. Educação para o lazer. São Paulo: Moderna, 1998a.

Lazer: concepções e significados. Licere, v.1, n.1, p.28-36, 1998 b.

DOMINGUES, S. C.; KUNZ, E.; ARAÚJO, L. C. G. Educação ambiental e educação física: possibilidades para a formação de professores. Revista Brasileira de Ciências do Esporte, v.33, n.3, p.559-571, 2011.

DOWN, L. Adressing the challenges of mainstreaming education for sustainable development in higher education. International Journal of Sustainability in Higher Education, v.7, n.4, p.390-399, 2006.

FARIAS, C. R. O. A produção da política curricular nacional para a educação superior diante do acontecimento ambiental: problematizações e desafios. 2008. 215 p. Tese (Doutorado) - Programa de Pós-Graduação em Educação, Universidade Federal de São Carlos, São Carlos, 2008. 
FIORI, E. M. Conscientização e educação. Educação e Realidade. Porto Alegre: UFRGS. v.11, n.1. jan/jun. 1986. p.3-10.

FRANCIS, C. Critical pedagogy, ecoliteracy and planetary crisis: the ecopedagogy movement. Environmental Education Research, v.17, n.5, p.705-708, 2011.

GHIRALDELLI JÚNIOR, P. Educação física progressista: a pedagogia crítico-social dos conteúdos e a educação física brasileira. São Paulo: Loyola, 1991. (Coleção Espaço, v.10).

GUIMARÃES, S. S. M. et al. Educação física no ensino médio e as discussões sobre meio ambiente: um encontro necessário. Revista Brasileira de Ciências do Esporte, v.28, n.3, p.157-172, 2007.

JOHNSON, SUE. Higher education and sustainable development: paradox and possibility. Environmental Education Research, v.17, n.2, p.281-284, 2011.

KYBURZ-GRABER, R.; HOFER, K.; WOLFENSBERGER, B. Studies on a socioecological approach to environmental education: a contribution to a critical position in the education for sustainable development discourse. Environmental Education Research, v.12, n.1, p.101-114, 2006.

LEITE, D. M. T.; CAETANO, C. A. Educação física, esporte e lazer na natureza: preservação, modismo, apologia. Será tudo isso? Motrivivência, v.26, n.22, p.137-143, Jun. 2004.

LOPES, J. S. L. Sobre processos de "ambientalização" dos conflitos e sobre dilemas da participação. Horizontes Antropológicos, v. 12, n.25, jan./jun., 2006, p.31-64. Porto Alegre.

MARCELLINO, N. C. Lazer e educação. 6. ed. Campinas: Papirus, 2000.

Lazer: concepções e significados. Licere, v.1, n.1, p.37-43, 1998.

MARINHO; A.; INÁCIO, H. L. D. Educação física, meio ambiente e aventura: um percurso por vias instigantes. Revista Brasileira de Ciências do Esporte, v.28, n.3, p.55-70, 2007.

MENDES, M. I. B. S.; NÓBREGA, T. P. Cultura de movimento: reflexões a partir da relação entre corpo, natureza e cultura. Pensar a Prática, v.12, n.2, p.1-10, maio/ago. 2009.

MOORE, J. Seven recommendations for creating sustainability education at the university level: a guide for change agents. International Journal of Sustainability in Higher Education, v.6, n.4, p.326-339, 2005.

MORAES, R. Uma tempestade de luz: a compreensão possibilitada pela análise textual discursiva. Ciência e Educação, v.9, n.2, p.191-211. 2003. 
O'CONNELL, T. S.; POTTER, T. G.; CURTHOYS, P. A call for sustainability education in post-secondary outdoor recreation programs. International Journal of Sustainability in Higher Education, v.6, n.1, p.81-94, 2005.

OSBORNE, R.; BATISTA, W. A. Educação Física na década da Educação para o Desenvolvimento Sustentável. Motriz, v.16, n.1, p.28-36, jan./mar. 2010.

OSBORNE, R.; SILVA, C. A. F.; VOTRE, S. J. Educação física, esporte e desenvolvimento sustentável. Pensar a Prática, v.14, n.1, p.1-14, 2011a.

OSBORNE, R. et al. Análise de artigos sobre meio ambiente e sustentabilidade em periódicos nacionais de Educação Física. Lecturas, Educación Física y Deportes, Ano 16, n.155, p.1-9, 2011 b.

PAYNE, P. G.; RODRIGUES, C. Environmentalizing the curriculum: a critical dialogue of south-north framings. Perspectiva, v.30, n.2, p.411-444, 2012.

PINTO, L. M. S. M. Lazer: concepções e significados. Licere, v.1, n.1, p.18-27, 1998.

RODRIGUES, C. A ambientalização curricular da educação física nos contextos da pesquisa acadêmica e do ensino superior. [tese]. São Carlos: Universidade Federal de São Carlos, Programa de Pós-Graduação em Educação; 2013.

Ambientalização dos currículos de educação física no ensino superior. Motriz, v.18, n.3, p. 557-570, 2012a.

RODRIGUES, C. As práticas de lazer diante do acontecimento ambiental: processos de ambientalização e a compreensão do lazer enquanto prática social. Licere, v.15, n.1, p.1-22, 2012 b.

; SILVA, R. A. Encontros contemporâneos entre lazer e educação ambiental: um possível caminho para a educação ambiental pelo lazer. Lazer e Sociedade, v.3, p.9-24, 2011. (Lazer e Ambiente: propostas, tendências e desafios).

RODRIGUES, L. H.; DARIDO, S. C. Educação Física escolar e meio ambiente: reflexões e aplicações pedagógicas. Lecturas, Educación Física y Deportes, Ano 11, n.100, p.1-4, set. 2006.

SÉRGIO, M. A racionalidade epistémica na educação física do século XX. In: SÉRGIO, M. e. col. O sentido e a acção. Lisboa: Instituto Piaget, 1999. p.11-30. (Coleção Epistemologia e Sociedade).

SHERREN, K. A history of the future of higher education for sustainable development. Environmental Education Research, v.14, n.3, p.238-256, 2008.

SILVA, F. W.; SILVA, A. M.; INÁCIO, H. L. D. A Educação Física frente a temática ambiental: alguns elementos teórico-metodológicos. Motrivivência, v.20, n.30, p.4460, Jun. 2008. 
SILVA, M. A. S. S.; GARCIA, M. A. L.; FERRARI, S. C. M. Memórias e brincadeiras na cidade de São Paulo nas primeiras décadas do século XX. São Paulo: Cortez, 1989.

SOARES, C. L. Educação Física: raízes européias e Brasil. 2. ed. Campinas: Autores Associados, 2001.

SOUZA, M. S.; LARA, G. S. Prática pedagógica em educação física e a educação ambiental. Pensar a Prática, v.14, n.2, p.1-11, 2011.

STEVAUX, R. P.; RODRIGUES, C. Com-vivência, educação e lazer: construindo processos educativos a partir da diversidade cultural. In: COLÓQUIO INTERNACIONAL EDUCAÇÃO E CONTEMPORANEIDADE, 6, São Cristóvão. Anais... São Cristóvão, 2012.

Os aspectos educacionais do jogo e o desenvolvimento do indivíduo. Lecturas

Educación Física y Deportes, Buenos Aires, v. 129, p. 1-9, 2009.

STUBBS, W.; SCHAPPER, J. Two approaches to curriculum development for educating for sustainability and CSR. International Journal of Sustainability in Higher Education, v.12, n.3, p.259-268, 2011.

TAVARES, F. J. P. A Educação Ambiental na formação de professores de Educação Física: uma emergente conexão. Lecturas, Educación Física y Deportes, v. 9, n.61, p.1-5, Jun. 2003.

LEVY, M. I. C. Implementação da educação ambiental na graduação de professores de educação física: uma reflexão. Revista Eletrônica do Mestrado em Educação Ambiental, p. 331-341, 2001.

VARGAS, J. E. N.; TAVARES, F. J. P. A Educação Ambiental no contexto da Educação Física Escolar. Lecturas, Educación Física y Deportes, v. 10, n.69, p.1-5, fev. 2004.

\section{Endereço do Autor:}

Cae Rodrigues

Rua Heriberto Rezende Gois, n.1105, ap.301

Coroa do Meio

Aracaju - SE - CEP: 49035-380

Endereço Eletrônico: cae_jah@ hotmail.com 